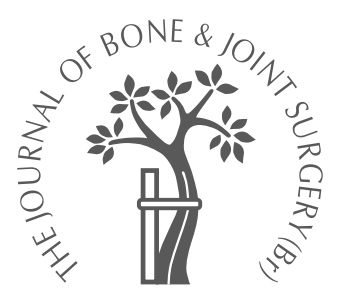

K. Kazuki,

K. Hiroshima,

K. Kawahara

From Osaka City

University Medical

School and Osaka

National Hospital,

Osaka, Japan

\title{
Ulnar focal cortical indentation
}

\author{
A PREVIOUSLY UNRECOGNISED FORM OF ULNAR DYSPLASIA
}

K. Kazuki, MD, Orthopaedic Surgeon, Associate Professor Department of Orthopaedic Surgery, Osaka City University Graduate School of Medicine, 1-4-3 Asahimachi, Abeno-ku, Osaka 545-8585, Japan.

K. Hiroshima, MD, Orthopaedic Surgeon, Professor and Director Department of Orthopaedic Surgery

K. Kawahara, MD, Pathologist

Department of Pathology Osaka National Hospital, 2-1 14 Hoenzaka, Chuo-ku, 5400006, Japan.

Correspondence should be sent to Dr K. Kazuki; e-mail: kkazuki@med.osaka-cu.ac.jp

(c)2005 British Editorial Society of Bone and Joint Surgery doi:10.1302/0301-620X.87B4. $15141 \$ 2.00$

$J$ Bone Joint Surg [Br] 2005;87-B:540-3.

Received 13 November 2003 Accepted after revision 15 April 2004

Deformity of the forearm due to growth disturbance of the ulna occurs in a number of conditions such as ulnar deficiency, multiple exostoses, and neurofibromatosis. We report a previously unrecognised form, caused by focal cortical indentation.

We have treated five children with this condition, three girls and two boys; the mean age at presentation was 5 years ( 2 to 8 ). The deformity was first recognised about the age of two years, and progressed gradually. The radiological findings were the same in all cases. The focal cortical indentation was seen at the distal end of the ulna with anteromedial bowing and dysplasia. The radial head was dislocated posterolaterally. In one patient the histological findings at the site of indentation were of a fold of tissue resembling periosteum, which interfered with enchondral ossification. Treatment by ulnar lengthening using an external fixator and osteotomy which corrected both the ulnar deformity and reduced the dislocated radial head in two cases gave the best results.

We report five patients presenting with a deformity of the forearm due to ulnar dysplasia associated with focal cortical indentation at the distal end of the ulna. This condition differs from previously described forms of ulnar dysplasia.

\section{Patients and Methods}

Between 1965 and 2000, we treated five patients, three girls and two boys with a progressive deformity of the forearm, cubitus varus and similar radiographic findings. The mean age at presentation was five years (2 to 8 ). The left forearm was involved in four and the right in one. None had trauma to the affected arm. The condition was not reported at birth but appeared during growth. Radiographs showed a focal cortical indentation at the distal end of the ulna (Fig. 1 ) in all patients. The indentation was on the anteromedial aspect and extended in a proximal and posterolateral direction. Longitudinal growth of the ulna was disturbed with anteromedial bowing. The radial head was dislocated posterolaterally with bowing of the radius but no other growth disturbance. No abnormalities were seen in the carpus or fingers. Operative treatment depended on the age at presentation and the decision of the surgeon (Table I). All except one patient had reached skeletal maturity by final follow-up.

\section{Results}

In the first patient (case 1), a series of procedures was attempted but the ulnar bowing persisted at follow-up. Cases 2 and 3 were treated by converting the two-bone forearm to a one-bone forearm. At final follow-up, the bowing was corrected but the forearm was short, with limitation of rotation. In case 3 , a specimen taken from the area of focal cortical indentation seen on the radiographs, was obtained during resection and showed a fold of tissue resembling periosteum reaching to the ulnar bone marrow. The abnormal tissue extended to the epiphysis, and interfered with enchondral ossification (Fig. 2).

Case 4 presented at the age of eight years with a deformity of the forearm and cubitus varus. She was an identical twin. Her grandfather had first noticed a deformity of the left elbow at the age of two years. The deformity progressed and ulnar lengthening with an external fixator was undertaken. After $3 \mathrm{~cm}$ of lengthening, the body of the external fixator body removed and manual correction of the ulna with repositioning of the radial head was performed retaining the fixator pins which were fixed with bone cement until the distracted callus matured. The focal cortical indentation was no longer seen on the radiographs taken after removal of the pins. At final follow-up at the age of 17 years, nine years after operation, the deformity was no longer 


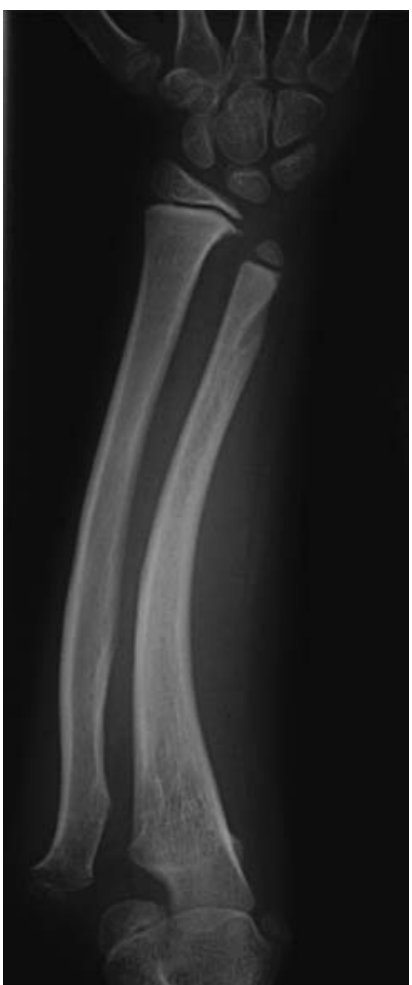

Fig. 1a

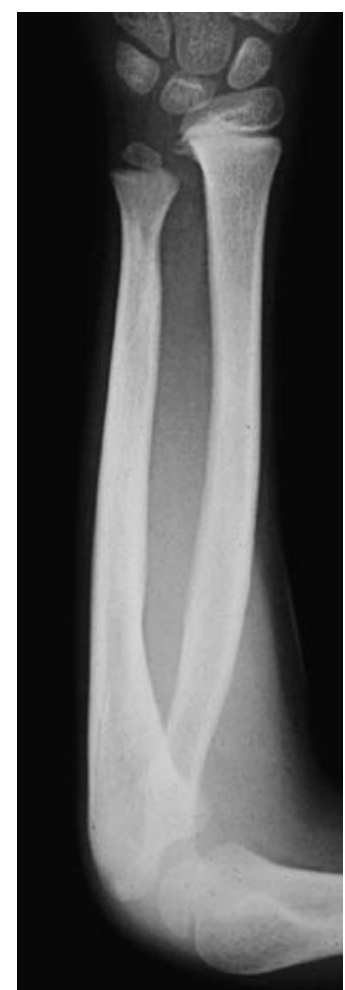

Fig. 1b

Pre-operative radiographs of case 4 , a) AP and b) lateral views. There is focal cortical indentation of the distal ulna with anteromedial bowing. The radial head is dislocated posterolaterally.
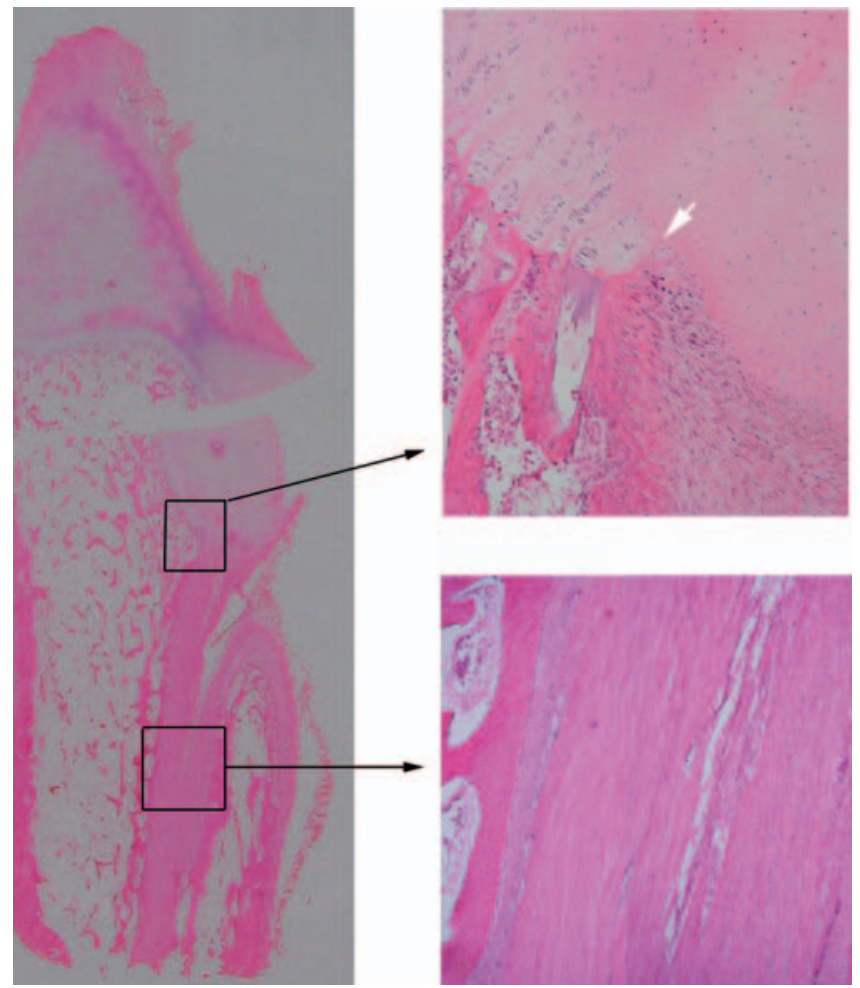

Fig. 2

Histological findings of case 3. A fold of tissue resembling periosteum reached to the epiphysis and enchondral ossification was obstructed by this lesion (white arrow); (x 100). clinically detectable, and the movements of the elbow and rotation of the forearm were full. The radiographs showed no recurrence of the focal cortical indentation.

Case 5 presented at the age of seven years with a deformity of the elbow; his grandfather had noticed the deformity. The right forearm showed ulnar bowing with a prominence laterally at the elbow. Radiographs showed ulnar bowing, with a distal focal indentation and dislocation of the radial head, as in the previous cases. Ulnar lengthening with a unilateral hinged external fixator was undertaken. After $2.8 \mathrm{~cm}$ of lengthening, the joint of the external fixator was relaxed, and manual correction of the ulna with repositioning of the radial head was performed. The external fixator was locked in the corrected position

Table I. Operative treatments and clinical results

\begin{tabular}{|c|c|c|c|c|c|c|c|c|c|c|}
\hline \multirow[b]{3}{*}{ Case } & \multirow{3}{*}{$\begin{array}{l}\text { Year of } \\
\text { first } \\
\text { operation }\end{array}$} & \multirow{3}{*}{$\begin{array}{l}\text { Age } \\
\text { at first } \\
\text { operation } \\
\text { (yrs) }\end{array}$} & \multirow{3}{*}{ Gender } & \multirow{3}{*}{$\begin{array}{l}\text { Affected } \\
\text { side }\end{array}$} & \multirow{3}{*}{ Surgical procedure(s) $)^{*}$} & \multicolumn{4}{|c|}{ Forearm at follow-up } & \multirow{3}{*}{$\begin{array}{l}\text { Follow-up } \\
\text { (yrs after } \\
\text { operation) }\end{array}$} \\
\hline & & & & & & \multirow[b]{2}{*}{ Deformity } & \multirow[b]{2}{*}{ Length $^{\dagger}(\%)$} & \multicolumn{2}{|c|}{ Range of movement $(\%)^{\dagger}$} & \\
\hline & & & & & & & & Pronation & Supination & \\
\hline 1 & 1965 & 5 & $\mathrm{~F}$ & Left & $\begin{array}{l}\text { Ulnar lengthening by bone } \\
\text { graft; internal fixation with } \\
\text { bone graft; corrective osteot- } \\
\text { omy of radius and ulna with } \\
\text { radial head resection }\end{array}$ & Remained & 91 & 25 & 78 & 13.2 \\
\hline 2 & 1973 & 3 & M & Left & $\begin{array}{l}\text { Corrective osteotomy of radius } \\
\text { with distal ulnar resection } \\
\text { Radial head resection } \\
\text { One-bone forearm }\end{array}$ & Corrected & 81 & -13 & 50 & 29.6 \\
\hline 3 & 1977 & 5 & $\mathrm{~F}$ & Left & One-bone forearm & Corrected & 86 & -25 & 61 & 20.1 \\
\hline 4 & 1993 & 8 & $\mathrm{~F}$ & Left & Ulnar lengthening by callotasis & Corrected & 97 & 94 & 100 & 9.2 \\
\hline 5 & 2000 & 7 & $\mathrm{M}$ & Right & Ulnar lengthening by callotasis & Corrected & 95 & 100 & 100 & 2.8 \\
\hline Mean & & 6 & & & & & & & & 15.0 \\
\hline
\end{tabular}

* only major procedures are listed

$\dagger$ percentage of unaffected side 


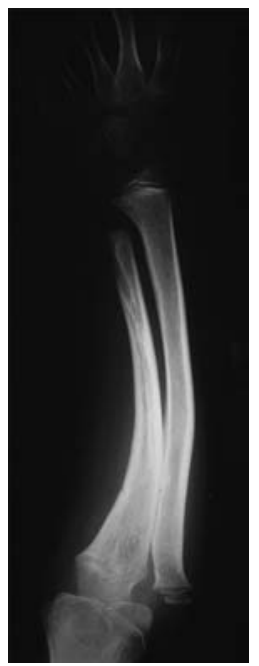

Fig. 3a

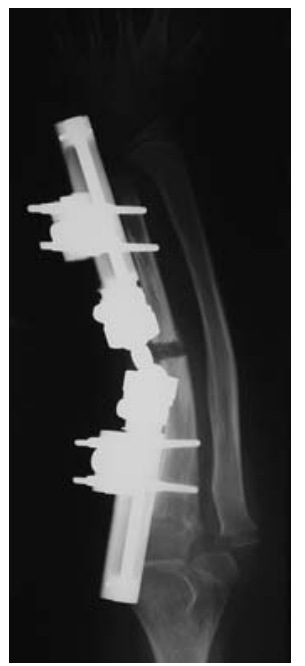

Fig. 3b

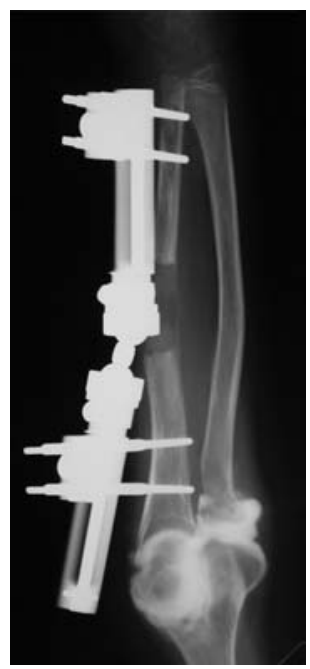

Fig. 3c

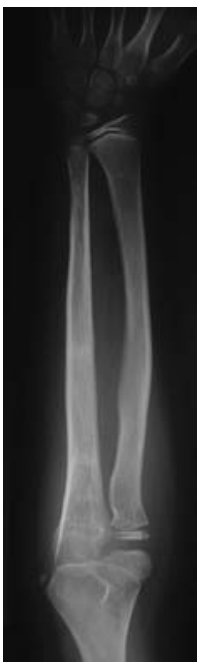

Fig. 3d

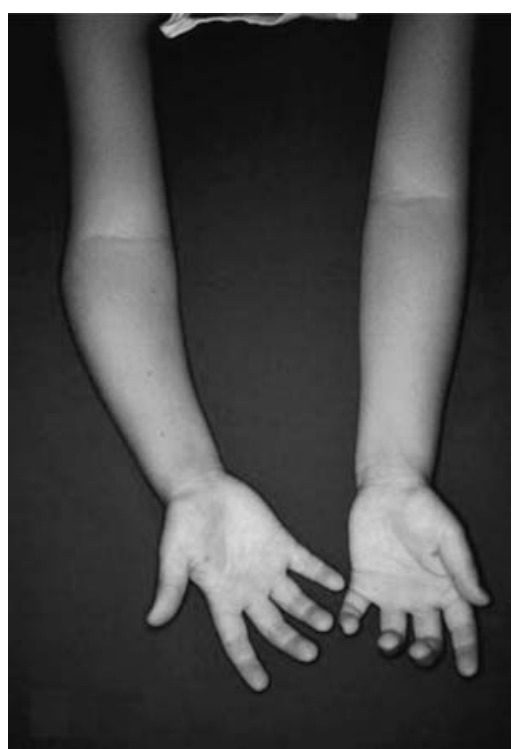

Fig. 3e

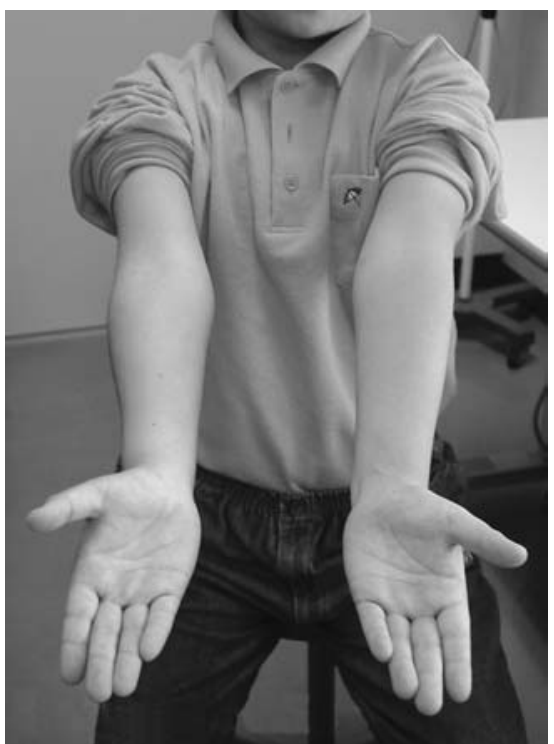

Fig. $3 f$

Anteroposterior radiograph of case 5, a) pre-operatively; b) during callus distraction; c) corrective osteotomy after callus distraction; d) at final follow-up; e) clinical appearance pre-operatively; f) clinical appearance 2.8 years post-operatively.

until the distraction callus matured. The focal cortical indentation was no longer seen on radiographs taken after removal of the pins. At final follow-up, 2.8 years post-operatively at the age of ten years, the forearm and elbow deformities were corrected, with a similar appearance to the unaffected side, without limitation of movement of the elbow or rotation of the forearm. The focal cortical indentation had disappeared as had the growth disturbance of the ulna (Fig. 3).

\section{Discussion}

Deformity of the forearm owing to a growth disturbance of the ulna may occur in a number of conditions such as ulnar deficiency, ${ }^{1}$ multiple exostoses, ${ }^{2,3}$ and neurofibromatosis. ${ }^{4,5}$
We believe that the type of ulnar dysplasia described here has not been reported before. Histological examination was undertaken in only one case, but we feel that all five cases represent the same entity with similar clinical and radiological findings.

The fold of dense connective tissue resembling periosteum found at histological examination seemed to have disturbed the longitudinal growth of the ulna on the palmar and ulnar side. Bowing of the radius with slow dislocation of the radial head occurred secondary to the ulnar bowing. It is not clear why part of the lesion which disturbed ulnar growth became indented into the ulnar bone marrow. Perhaps tissue at the insertion of the pronator quadratus muscle into the distal ulna entered the marrow at the site of 
the focal cortical indentation. The lesion occurred in one identical twin (case 4) but not the other making a hereditary cause unlikely.

The best results of treatment were by ulnar lengthening with an external fixator followed by corrective osteotomy. This corrected the ulnar deformity three-dimensionally and simultaneously reduced the dislocation of the radial head. We did not use the Ilizarov technique. ${ }^{6}$ Flatt $^{1}$ created a single-bone forearm for type II ulnar deficiency. In almost all patients the movements of the elbow, forearm, and wrist were satisfactory. However, in our view, in cases of ulnar bowing due to focal cortical indentation of the ulna, creating a one-bone forearm should be used only as a salvage procedure as in case 2 . Case 3 was operated on in the 1970 s when ulnar lengthening by callus distraction was not widely used. Long-term follow-up showed that the onebone forearm was shorter than the other side, with some limitation of rotation of the forearm.

The course of the focal cortical indentation of the ulna was as follows. The indentation had disappeared on followup radiographs in cases 4 and 5 . In the latter two, distal pins were inserted at the removed site of the indentation, which was not seen on radiographs after the pins had been removed. This suggests that the pins cut into and destroyed the lesion, so that subsequent longitudinal growth of the ulna was normal. Thus the growth disturbance caused by this lesion would seem to be different from that of early epiphyseal arrest, and that bone formation can occur during growth.

The clinical and radiological characteristics of our patients appear similar to those described by Bell et $\mathrm{al}^{7}$ in tibia vara with focal fibrocartilaginous dysplasia, but the histological findings are different. Focal fibrocartilaginous dysplasia is at the metaphysis, and does not reach the epiphysis. Fibrocartilage is found histologically at the abnormal radiographic areas whereas focal cortical indentations reach the epiphysis, and the histological findings are of a fold of tissue resembling periosteum not fibrocartilage. In both lesions, bone growth is probably disturbed by aberrant congenital tissue. Focal cartilaginous dysplasia has been reported in the upper limb and spontaneous healing can occur. ${ }^{8,9}$ By contrast, the forearm deformity with dislocation of the radial head which we describe is progressive and therefore we believe a different entity.

No benefits in any form have been received or will be receive from a commercial party related directly or indirectly to the subject of this article.

\section{References}

1. Flatt AE. The care of congenital hand anomalies. Second ed. St. Louis: Quality Medical Publishing 1994:411-24.

2. Burgess RC, Cates H. Deformities of the forearm in patients who have multiple cartilaginous exostosis. J Bone Joint Surg [Am] 1993;75-A:13-18.

3. Rodgers WB, Hall JE. One-bone forearm as a salvage procedure for recalcitrant forearm deformity in hereditary multiple exostoses. J Pediatr Orthop 1993;13:587-91.

4. Maffulli N, Fixsen JA. Pseudoarthrosis of the ulna in neurofibromatosis: a report of four cases. Arch Orthop Trauma Surg 1991;110:204-7.

5. Wood VE. Congenital pseudarthrosis of the forearm. In: Green DP, Hotchkiss RN, Pederson WC, eds. Green's operative hand surgery. Vol. 1, Fourth ed. New York: Churchill Livingstone, 1999:544-51.

6. Paley D, Kelly D. Lengthening and deformity correction in the upper extremities. Atlas Hand Clin 2000;5:117-72.

7. Bell SN, Campbell PE, Cole WG, Menelaus MB. Tibia vara caused by focal fibrocartilaginous dysplasia: three case reports. J Bone Joint Surg [Br] 1985;67-B:780-4.

8. Lincoln TL, Birch JG. Focal fibrocartilaginous dysplasia in the upper extremity. $J$ Pediatr Orthop 1997;17:528-32.

9. Choi IH, Kim CJ, Cho T-J, et al. Focal fibrocartilaginous dysplasia of long bones: report of eight additional cases and literature review. J Pediatr Orthop 2000;20:421-7. 